\title{
Fuzzy Inference System dengan Metode Mamdani untuk Prediksi Kanker Payudara
}

\author{
Normalisa \\ Teknik Informatika, Universitas Pamulang \\ dosen00377@unpam.ac.id
}

\begin{abstract}
Abstrak
Kanker payudara sampai dengan saat ini masih menjadi suatu penyakit yang menakutkan khususnya bagi kaum perempuan karena dapat mengancam nyawa, pendeteksian secara dini dapat ditempuhkan agar pengobatan secepatnya dapat dilakukan dan penyakit tidak berkembang lebih jauh. Deteksi saat ini yang ada adalah dengan scan mammography akan tetapi dengan scan ini tidak semua lapisan usia dapat melakukannya karena hanya seseorang dengan usia minimal 35 tahun keataslah yang dapat melakukannya sedangkan wanita dibawah umur tersebut pun dapat juga terkena kanker. Juga didapatkannya hasil yang kurang optimal dari output scan tersebut, seperti waluupun seseorang sudah divonis kanker namun setelah dilakukan penyelidikan lebih lanjut ada juga kalanya ternyata tidak terdapat kanker samasekali.

Sistem ini dikembangkan dengan OOAD (Object Oriented Analysis System) yang terbagi atas empat tahapan yaitu analisis, desain, implementasi dan testing. Untuk perhitungan data digunakan metode dengan Fuzzy Inference System yang dipadukan dengan aplikasi memakai joomla. Pengujian sistem dilakukan dengan metode blackbox dan whitebox.
\end{abstract}

Prediksi dilakukan dengan cara memasukkan parameter-parameter yang ada sehingga diperoleh kesimpulan seberapa besar tingkat penyakit tersebut.

\section{Kata kunci: Scan mammographi, Prediksi, OOAD dan Fuzzy Inference System}

\section{Pendahuluan}

Kanker adalah kelompok penyakit yang tergolong agresif (tumbuh dan terbagi hingga kebatas normal), invasive (menyerang dan menghancurkan jaringan terdekat), dan terkadang metastatis (menyebarkan ke bagian tubuh yang lain). Kanker payudara adalah kanker kelenjar jaringan payudara. Diseluruh dunia, kanker payudara adalah kanker penyebab kematian nomor 5 (setelah kanker paru-paru, perut, hati dan kanker usus). Pada tahun 2005, kanker payudara meyebabkan 502, 000 kematian (7 persen penyebabkan kematian, hampir 1 persen semuanya meninggal) didunia. Deteksi dini dan terapi bertahap yang tepat mempunyai kontribusi terhadap tingkat keberhasilan untuk melawan kanker (Sukla, 2010 : p315).

Ini sudah menjadi topik kesehatan paling dicari oleh pengguna di internet. Studi sebelumnya telah mengevaluasi pengguna di internet yaitu wanita yang terkena kanker payudara dan kualitas dari situs yang dipilih. Survey terbaru menunjukkan bahwa 40 dari 54 persen pasien mengakses informasi medis lewat internet dan informasi tersebut mempengaruhi pilihan mereka untuk perawatan. Berdasarkan survey dari pasien kanker payudara yang selamat, sebuah kuisioner penilaian kualitas hidup telah dikirim kepada 325 pasien kanker payudara. Diperoleh 66 persen respon yang valid. Berdasarkan respon ini, 169 wanita telah melewati masa menopose. Lebih dari 50 persen wanita yang telah menopose menderita berbagai gejalanya, tetapi sedikit yang mengambil perawatan untuk menghilang gejala ini. Pengobatan utama untuk perawatan kanker payudara adalah membedah pada lokasi tumor tersebut, dengan kemungkinan anjuran terapi hormone (dengan tamoxifen atau aromatase inhibitor), kemoterapi, dan/atau radioterapi.

Kanker payudara pada dasarnya dapat menyerang pada pria maupun wanita. Meskipun kasus kanker payudara pada pria lebih jarang terjadi, tetapi riset terbaru mengindikasikan bahwa kanker payudara pada pria mungkin bisa lebih mematikan ketimbang wanita. "Pria yang mengidap kanker payudara mungkin kurang mendapatkan perawatan standar, berbeda dengan yang selama ini para wanita dapatkan," kata penulis studi, Dr Jon Greif, seorang ahli bedah payudara di San Francisco Amerka Serikat. Greif mengatakan, tingkat kelangsungan hidup untuk pria yang memiliki kanker payudara secara keseluruhan lebih rendah ketimbang wanita, 
setidaknya saat didiagnosa pada tahap awal. Rencananya Greif akan mempresentasikan temuannya dalam sebuah pertemuan tahunan American Society of Breast Surgeons di Phoenix. Greif dan rekan menegaskan, walau bagaimanapun, beberapa perbedaan yang mereka temukan mungkin tidak dapat dibuktikan dalam praktek klinis. Greif mengakui, riset yang dilakukannya memiliki keterbatasan karena mereka menggunakan database pasien kanker payudara yang sudah meninggal namun tidak diketahui apa penyebab kematiannya. Jadi, sulit untuk mengetahui apakah mereka meninggal akibat kanker atau sesuatu yang lain. Banyak pria tidak menyadari bahwa mereka bisa terkena kanker payudara. Bahkan, data yang dimiliki American Cancer Society memperkirakan, ada sekitar 2.200 kasus baru kanker payudara pada laki-laki pada tahun ini. Diperkirakan, 410 orang akan meninggal karena kanker payudara pada tahun 2012 di Amerika Serikat.

Untuk melakukan deteksi di Rumah Sakit umumnya dan di Usada Insani khususnya seseorang diharuskan untuk berumur minimal 35 tahun sehingga menyebabkan seseorang yang kemungkinan ada penyakit kanker payudara dibawah usia tersebut tidak dapat melakukan deteksi dini. Adapun kendala lain dari scan mammography yaitu kurang optimalnya data yang dihasilkan karena hasil dari scan terkadang tidak terbukti kebenarannya. Seperti hasil mammography adalah iya menderita kanker atau tidak, seseorang yang sudah dinyatakan positif kanker setelah dilakukan pemeriksaan lebih lanjut ternyata tidak menderita dan begitupun sebaliknya.

Oleh karena itu, perlunya suatu aplikasi untuk pendeteksian dini untuk predeksi penyakit kanker payudara agar semua golongan usia dapat melakukannya dan juga hasil yang dicapai lebih optimal. Proses deteksi dilakukan dengan cara memasukkan parameter-parameter deteksi seperti usia, berat badan, konsumsi alkohol dan riwayat dalam garis keturunan lalu dilakukan perhitungan dengan metode logika fuzzy. Dengan algoritma ini hasil prediksi menunjukkan angka resiko kanker sehingga hasil output yang dihasilkan dari prediksi lebih optimal.

Logika fuzzy juga banyak digunakan dalam bidang ilmu informatika medis baik yang berupa expert system maupun intelligent medical diagnostic system dalam menentukan diagnosa penyakit untuk membantu pasien dan tenaga medis (Santoso, 2008: p13). Dalam menentukan tingkat resiko kanker payudara dapat juga digunakan pemeriksaan penyaring berupa usia, berat badan, konsumsi alkohol dan riwayat hidup dalam garis keturunan (WHO, 2000: p1) yang bertujuan untuk memudahkan dalam identifikasi seseorang mempunyai penyakit kanker payudara. Oleh karena itu pada sistem yang akan dibangun akan digunakan model dengan logika fuzzy yang menggunakan sekumpulan if-then rule dengan pendekatan himpunan-himpunan fuzzy (fuzzy sets) dalam melakukan proses penalaran (Kusumadewi, 2009: p126).

\section{Metode Penelitian}

Proses yang diusulkan dengan metode mamdani adalah sebagai berikut;

Dalam penelitian ini diasumsikan bahwa usia, berat badan dan tekanan darah pada dasarnya menentukan rasio resiko kanker payudara. Jadi ketiga parameter tersebut akan dijadikan sebagai masukan untuk sistem yang dirancang.

\section{Fuzzification}

Dengan bantuan literatur data dan wawancara dengan dokter, maka dapat dijelaskan parameter untuk fuzzification input sebagai berikut:

1. Umur (muda, paruh baya dan tua)

2. IMT (kurang, normal, kelebihan, obesitas 1 dan obesitas 2)

3. Masukan alkohol (sangat sedikit, sedikit, banyak sangat banyak)

4. Resiko kanker payudara (sangat rendah, rendah, menengah, tinggi dan sangat tinggi) berikut:

Secara lebih detail dapat diuraikan sebagai

1. Umur

Tabel 1 Parameter Usia

\begin{tabular}{|c|c|}
\hline Nilai & Interval \\
\hline Muda & $<30$ \\
\hline Paruh baya & $40-50$ \\
\hline Tua & $>70$ \\
\hline
\end{tabular}

ekspresi untuk fungsi keanggotaan fuzzy: 


$$
\begin{aligned}
& \mu_{\text {muda }}(x)=\left\{\begin{array}{cc}
1 & x<30 \\
\frac{(40-x)}{10} & 30 \leq x \leq 40
\end{array}\right\} \\
& \mu_{\text {paru hbaya }}(x)=\left\{\begin{array}{cc}
\frac{(x-30)}{10} & 30 \leq x<40 \\
1 & 40 \leq x \leq 50 \\
\frac{(70-x)}{20} & 50 \leq x<70
\end{array}\right\} \\
& \mu_{\text {tua }}(x)=\left\{\begin{array}{cc}
\frac{(x-50)}{20} & 50 \leq x<70 \\
1 & x \geq 70
\end{array}\right\}
\end{aligned}
$$

Representasi dengan grafik dapat digambarkan sebagai berikut:

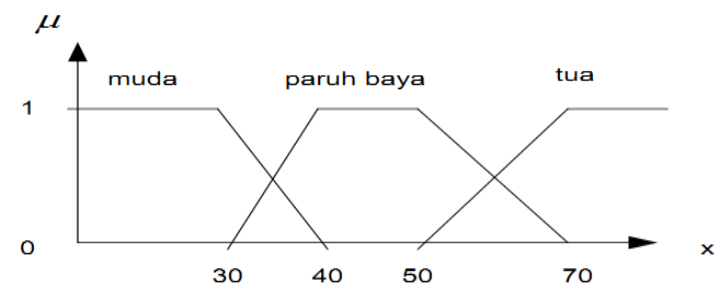

Input variabel umur

Gambar 1 Grafik Keanggotan Umur

2. Indeks Massa Tubuh (IMT)

Pengukuran berat badan disesuaikan dengan Indeks Masa Tubuh (body mass index) berdasarkan sumber dari World Health Organization yang telah dirujuk oleh Direktorat Bina Gizi Masyarakat Departemen Kesehatan Republik Indonesia untuk digunakan di Indonesia dengan menghitung berat badan dibagi dengan tinggi badan (dalam satuan meter) kuadrat.

Tabel 2 Parameter IMT

\begin{tabular}{|l|l|}
\hline Nilai & Interval \\
\hline Kurang & $<18,5$ \\
\hline Normal & $18,5-<25$ \\
\hline Kelebihan & $25-<30$ \\
\hline Obesitas 1 & $30-<35$ \\
\hline Obesitas 2 & $\geq 35$ \\
\hline
\end{tabular}

ekspresi untuk fungsi keanggotaan fuzzy:

$$
\begin{aligned}
& \mu_{\text {kurang }}(y)=\left\{\begin{array}{cc}
1 & y<18,5 \\
\frac{(18,5-y)}{18,5} & 0 \leq y<18,5
\end{array}\right\} \\
& \mu_{\text {normal }}(y)=\left\{\begin{array}{ll}
\frac{(y-18,5)}{6,5} & 18,5 \leq y<25 \\
\frac{(30-y)}{5} & 25 \leq y<30
\end{array}\right\} \\
& \mu_{\text {kelebi han }}(y)=\left\{\begin{array}{ll}
\frac{(y-25)}{5} & 25 \leq y<30 \\
\frac{(35-y)}{5} & 30 \leq y<35
\end{array}\right\} \\
& \mu_{\text {obesitas } 1}(y)=\left\{\begin{array}{cc}
\frac{(y-30)}{3} & 30 \leq y<33 \\
\frac{(35-y)}{2} & 33 \leq y<35
\end{array}\right\} \\
& \mu_{\text {obesitas } 2}(y)=\left\{\begin{array}{cc}
\frac{(y-30)}{5} & 30 \leq y<35 \\
1 & y \geq 35
\end{array}\right\}
\end{aligned}
$$

Representasi dengan grafik dapat digambarkan sebagai berikut:

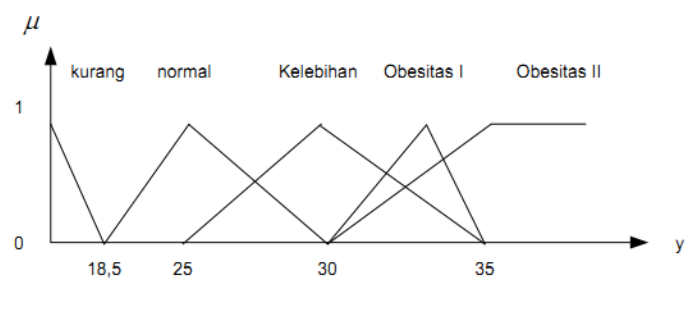

Input variabel index masa tubuh

Gambar 2 Grafik Keanggotan IMT

3. Masukan alkohol (sangat sedikit, sedikit, banyak sangat banyak)

Tabel 3 Parameter Masukan Alchohol

\begin{tabular}{|l|l|}
\hline Nilai & $\begin{array}{l}\text { Interval } \\
\text { dalam sehari }\end{array}$ \\
\hline Sangat Sedikit & $<1$ \\
\hline Sedikit & $1-<3$ \\
\hline Banyak & $3-5$ \\
\hline Sangat Banyak & $>5$ \\
\hline
\end{tabular}

ekspresi untuk fungsi keanggotaan fuzzy :

$$
\begin{aligned}
& (z)=\left\{\begin{array}{lc}
1-z & z<1 \\
\underline{1-z} & 0 \leq z<1
\end{array}\right\} \\
& \mu_{\text {sedikit }}(z)=\left\{\begin{array}{cl} 
& 1 \leq z<3 \\
\frac{z-1}{2} & 3 \leq z \leq 5
\end{array}\right\} \\
& \mu_{\text {banyak }}(z)=\left\{\begin{array}{ll}
\frac{(z-3)}{2} & 3 \leq z \leq 5
\end{array}\right\} \\
& \mu_{\text {sangat banyak }}(z)=\left\{\begin{array}{cc}
\frac{(z-5)}{1} & 5 \leq x \leq 6 \\
1 & z \geq 6
\end{array}\right\}
\end{aligned}
$$


Representasi dengan grafik dapat digambarkan sebagai berikut:

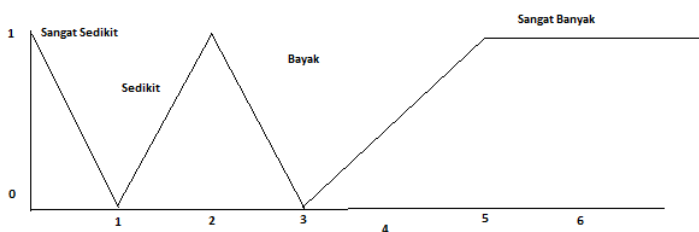

Gambar 3 Grafik Keanggotan Masukan Alkohol

Sedangkan untuk variable outputnya menghasilkan satu variable yaitu:

1. Resiko kanker payudara (sangat rendah, rendah, menengah, tinggi dan sangat tinggi)

Tabel 4

Parameter Resiko Kanker

\begin{tabular}{|l|c|}
\hline Nilai & $\begin{array}{c}\text { Interval } \\
\text { dalam \% }\end{array}$ \\
\hline Sangat rendah & $<20$ \\
\hline Rendah & $20-<40$ \\
\hline Menengah & $40-<60$ \\
\hline Tinggi & $60-70$ \\
\hline Sangat Tinggi & $>70$ \\
\hline
\end{tabular}
fuzzy:

ekspresi untuk fungsi keanggotaan

$$
\begin{aligned}
& \mu_{\text {sangatrenda } h}(r)=\left\{\begin{array}{cc}
0 & r<1 \\
\frac{(5-r)}{5} & 0 \leq r<5
\end{array}\right\} \\
& \mu_{\text {renda } h}(r)=\left\{\begin{array}{cc}
\frac{(r-2)}{3} & 2 \leq r<5 \\
\frac{(15-r)}{10} & 5 \leq r<15
\end{array}\right\} \\
& \mu_{\text {menenga } h}(r)=\left\{\begin{array}{cc}
\frac{(r-5)}{10} & 5 \leq r<15 \\
\frac{(25-r)}{10} & 15 \leq r<25
\end{array}\right\} \\
& \mu_{\text {tinggi }}(r)=\left\{\begin{array}{cc}
\frac{(r-15)}{5} & 15 \leq r<20 \\
\frac{(35-r)}{15} & 20 \leq r<35
\end{array}\right\} \\
& \mu_{\text {sangattinggi }}(r)=\left\{\begin{array}{cc}
\frac{(r-35)}{10} & 25 \leq r<35 \\
1 & r \geq 35
\end{array}\right\}
\end{aligned}
$$

Representasi dengan grafik dapat digambarkan sebagai berikut:

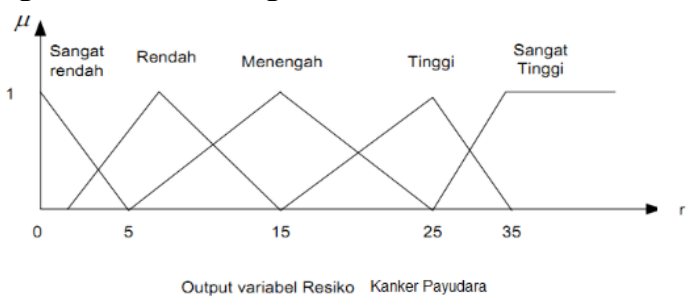

Gambar 4 Grafik Keanggotan Resiko Kanker Payudara

\begin{tabular}{|c|c|c|c|c|}
\hline \multirow{2}{*}{ ATURAN } & \multicolumn{3}{|c|}{ INPUT } & \multirow{2}{*}{$\begin{array}{c}\text { OUTPUT } \\
\text { Resiko } \\
\end{array}$} \\
\hline & Usia & IMT & K_Alkohol & \\
\hline Aturan 1 & Muda & Kurang & Sangat Sedikit & Sangat Rendah \\
\hline Aturan 2 & Muda & Kurang & Sedikit & Sangat Rendah \\
\hline Aturan 3 & Muda & Kurang & Banyak & Rendah \\
\hline Aturan 4 & Muda & Kurang & Sangat Banyak & Menengah \\
\hline Aturan 5 & Muda & Normal & Sangat Sedikit & Sangat Rendah \\
\hline Aturan 6 & Muda & Normal & Sedikit & Rendah \\
\hline Aturan 7 & Muda & Normal & Banyak & Menengah \\
\hline Aturan 8 & Muda & Normal & Sangat Banyak & Menengah \\
\hline Aturan 9 & Muda & Kelebihan & Sangat Sedikit & Rendah \\
\hline Aturan 10 & Muda & Kelebihan & Sedikit & Menengah \\
\hline Aturan 11 & Muda & Kelebihan & Banyak & Menengah \\
\hline Aturan 12 & Muda & Kelebihan & Sangat Banyak & Menengah \\
\hline
\end{tabular}

\section{Inference}

Berdasarkan hasil data di atas dapat disimpulkan menjadi rules sebagai berikut;

Tabel 5 Rules Inference 


\begin{tabular}{|c|c|c|c|c|}
\hline Aturan 13 & Muda & Obesitas 1 & Sangat Sedikit & Menengah \\
\hline Aturan 14 & Muda & Obesitas 1 & Sedikit & Menengah \\
\hline Aturan 15 & Muda & Obesitas 1 & Banyak & Tinggi \\
\hline Aturan 16 & Muda & Obesitas 1 & Sangat Banyak & Tinggi \\
\hline Aturan 17 & Muda & Obesitas 2 & Sangat Sedikit & Tinggi \\
\hline Aturan 18 & Muda & Obesitas 2 & Sedikit & Tinggi \\
\hline Aturan 19 & Muda & Obesitas 2 & Banyak & Tinggi \\
\hline Aturan 20 & Muda & Obesitas 2 & Sangat Banyak & Tinggi \\
\hline Aturan 21 & Paruh Baya & Kurang & Sangat Sedikit & Sangat Rendah \\
\hline Aturan 22 & Paruh Baya & Kurang & Sedikit & Rendah \\
\hline Aturan 23 & Paruh Baya & Kurang & Banyak & Rendah \\
\hline Aturan 24 & Paruh Baya & Kurang & Sangat Banyak & Menengah \\
\hline Aturan 25 & Paruh Baya & Normal & Sangat Sedikit & Rendah \\
\hline Aturan 26 & Paruh Baya & Normal & Sedikit & Rendah \\
\hline Aturan 27 & Paruh Baya & Normal & Banyak & Menengah \\
\hline Aturan 28 & Paruh Baya & Normal & Sangat Banyak & Menengah \\
\hline Aturan 29 & Paruh Baya & Kelebihan & Sangat Sedikit & Menengah \\
\hline Aturan 30 & Paruh Baya & Kelebihan & Sedikit & Menengah \\
\hline Aturan 31 & Paruh Baya & Kelebihan & Banyak & Tinggi \\
\hline Aturan 32 & Paruh Baya & Kelebihan & Sangat Banyak & Sangat Tinggi \\
\hline Aturan 33 & Paruh Baya & Obesitas 1 & Sangat Sedikit & Menengah \\
\hline Aturan 34 & Paruh Baya & Obesitas 1 & Sedikit & Menengah \\
\hline Aturan 35 & Paruh Baya & Obesitas 1 & Banyak & Tinggi \\
\hline Aturan 36 & Paruh Baya & Obesitas 1 & Sangat Banyak & Sangat Tinggi \\
\hline Aturan 37 & Paruh Baya & Obesitas 2 & Sangat Sedikit & Menengah \\
\hline Aturan 38 & Paruh Baya & Obesitas 2 & Sedikit & Tinggi \\
\hline Aturan 39 & Paruh Baya & Obesitas 2 & Banyak & Sangat Tinggi \\
\hline Aturan 40 & Paruh Baya & Obesitas 2 & Sangat Banyak & Sangat Tinggi \\
\hline Aturan 41 & Tua & Kurang & Sangat Sedikit & Rendah \\
\hline Aturan 42 & Tua & Kurang & Sedikit & Rendah \\
\hline Aturan 43 & Tua & Kurang & Banyak & Menengah \\
\hline Aturan 44 & Tua & Kurang & Sangat Banyak & Menengah \\
\hline Aturan 45 & Tua & Normal & Sangat Sedikit & Menengah \\
\hline Aturan 46 & Tua & Normal & Sedikit & Menengah \\
\hline Aturan 47 & Tua & Normal & Banyak & Tinggi \\
\hline Aturan 48 & Tua & Normal & Sangat Banyak & Tinggi \\
\hline Aturan 49 & Tua & Kelebihan & Sangat Sedikit & Menengah \\
\hline Aturan 50 & Tua & Kelebihan & Sedikit & Menengah \\
\hline Aturan 51 & Tua & Kelebihan & Banyak & Tinggi \\
\hline Aturan 52 & Tua & Kelebihan & Sangat Banyak & Sangat Tinggi \\
\hline Aturan 53 & Tua & Obesitas 1 & Sangat Sedikit & Tinggi \\
\hline Aturan 54 & Tua & Obesitas 1 & Sedikit & Tinggi \\
\hline Aturan 55 & Tua & Obesitas 1 & Banyak & Sangat Tinggi \\
\hline
\end{tabular}




\begin{tabular}{|l|l|l|l|l|} 
Aturan 56 & Tua & Obesitas 1 & Sangat Banyak & Sangat Tinggi \\
\hline Aturan 57 & Tua & Obesitas 2 & Sangat Sedikit & Tinggi \\
\hline Aturan 58 & Tua & Obesitas 2 & Sedikit & Tinggi \\
\hline Aturan 59 & Tua & Obesitas 2 & Banyak & Sangat Tinggi \\
\hline Aturan 60 & Tua & Obesitas 2 & Sangat Banyak & Sangat Tinggi \\
\hline
\end{tabular}

Defuzzification dengan metode mamdani:

$$
\begin{aligned}
& z=-\frac{\int_{z} z_{i} \mu(z) d z}{\int_{z} \mu(z) d z} \\
& z=-\frac{\sum_{j=1}^{n} z_{j} \mu\left(z_{j}\right)}{\sum_{j=1}^{n} \mu\left(z_{j}\right)}
\end{aligned}
$$

\section{Pembahasan}

Pada saat sistem dijalankan maka yang akan muncul pertama kali adalah form home

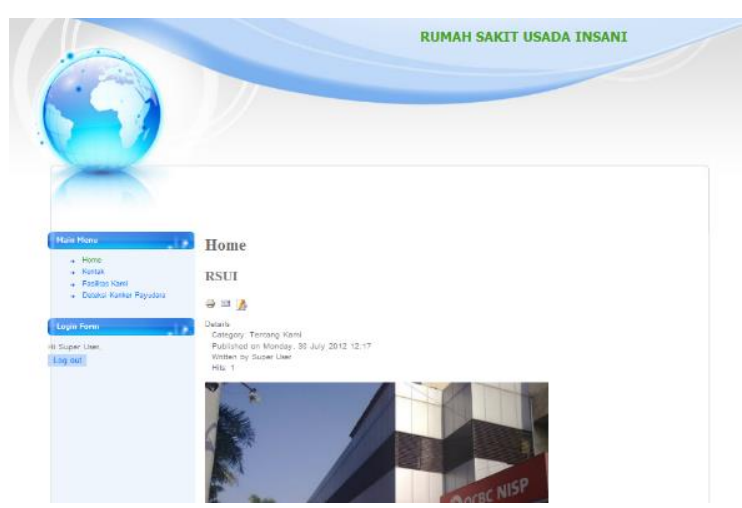

Gambar 5 Gambar Tampilan : Menu Home

Menu Tambahan terdapat menu Kontak dan menu Fasilitas

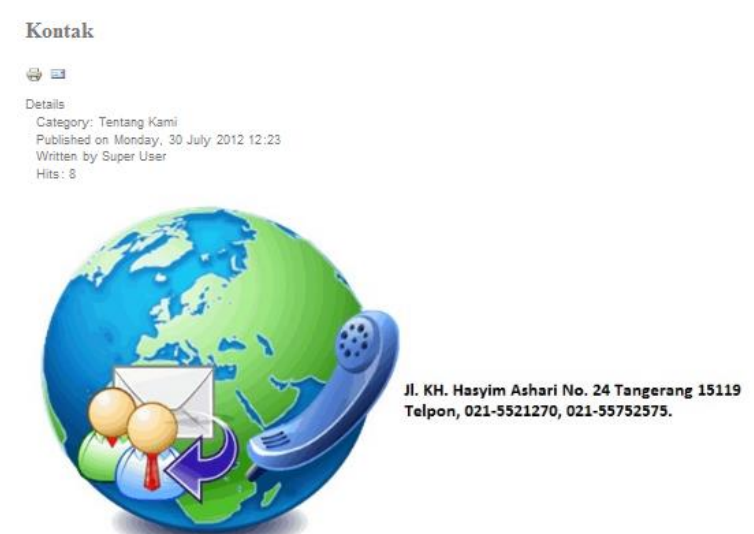

Gambar 6 Gambar Tampilan : Menu Kontak
Fasilitas

a

Details

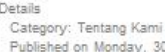

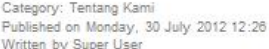

Hits

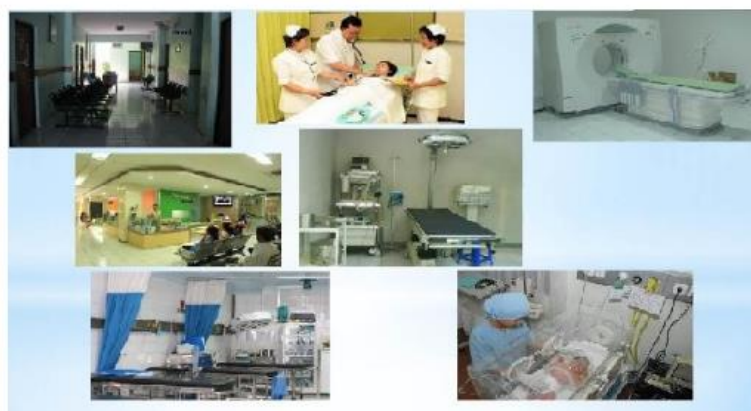

FASILITAS-FASILITAS KAMI

Gambar 7 Gambar Tampilan : Menu Fasilitas

\subsection{Tampilan Input}

Form input meliputi form registrasi dipergunakan untuk pengisian data pasien untuk pertama kali, form login digunakan pada saat akan mengakses sistem deteksi harus login terlebih daulu dan form isian deteksi dipergunakan untuk pengisian data untuk keperluan pendeteksian kanker payudara.

Berikut gambar tampilannya;

\section{Menambah Pasien}

\begin{tabular}{|l|l|}
\hline NP & \\
\hline Nama & \\
\hline Tanggal Lahir (D-M-Y) & \\
\hline Umur & \\
\hline Jenis Kelamin & \\
\hline Pekerjaan & \\
\hline agama & \\
\hline status & \\
\hline alamat & \\
\hline \hline Simpan & \\
\hline \hline
\end{tabular}

Gambar 8 Gambar Tampilan : Form Registrasi 


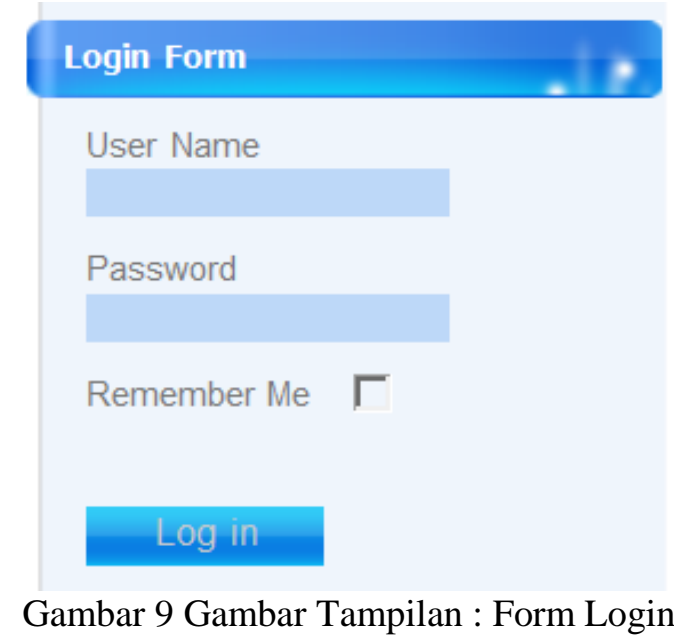

Isi Data Deteksi

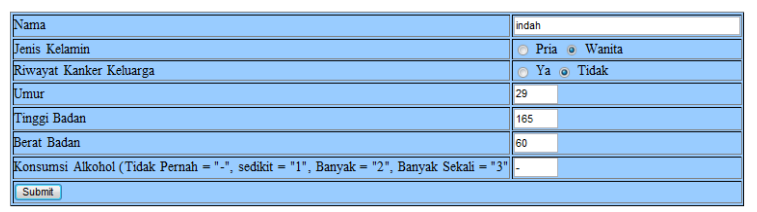

Gambar 10 Gambar Tampilan : Form Isian Deteksi

\subsection{Tampilan Output}

Form output menghasilkan form hasil deteksi dari proses deteksi kanker payudara dan form laporan.

Berikut gambar tampilannya;

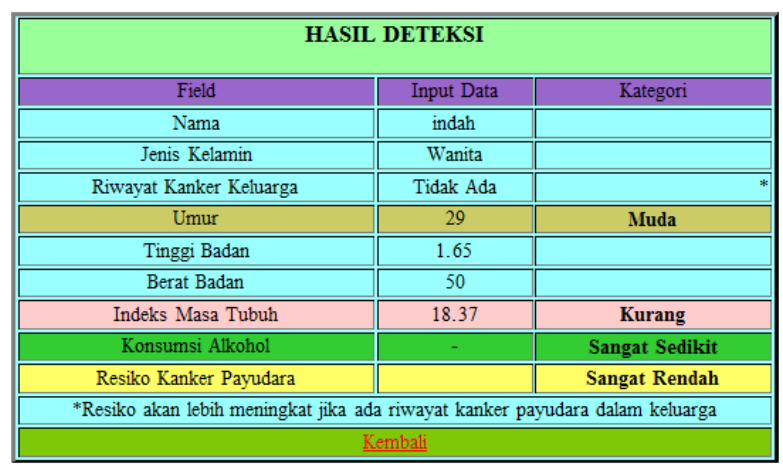

Gambar 11 Gambar Tampilan : Form Hasil Deteksi

Database: usadadb, Table: isian

\begin{tabular}{|l|c|c|r|r|r|r|}
\hline nama & jk & riwayat & umur & tingai & berat & alko \\
\hline indah & Wanita & Tidak Ada & 29 & 165 & 50 & 0 \\
\hline
\end{tabular}

Gambar 12 Gambar Tampilan : Form Laporan

\section{Kesimpulan}

Berdasarkan hasil penelitian dan pembahasan yang disampaikan pada bagian sebelumnya, maka dapat ditarik beberapa kesimpulan seperti berikut: a. Implementasi Fuzzy Inference System (FIS) dengan metode Mamdani diterapkan dengan cara mengidentifikasi parameterparameter masukan dalam proses fuzzification lalu parameter-parameter tersebut di masukkan dalam rules yang terbentuk dari proses inference setelah itu dilakukan proses defuzzification yaitu menghitung rules dan sample data dengan rumus Mamdani sehingga mendapatkan hasil deteksi.

b. Analisis dan desain sistem pada proses prediksi kanker payudara di lingkungan Rumah Sakit Usada Insani dilakukan dengan menggunakan metodologi $O O A D$ yang dijabarkan menjadi empat tahap yaitu definisi kebutuhan, perancangan sistem, implementasi serta integrasi dan pengujian sistem. Pada tahap definisi kebutuhan dapat diketahui bahwa sistem memerlukan layar masukan pasien, login dan isian deteksi. Untuk keluaran, sistem menghasilkan laporan hasil deteksi. Pada tahap perancangan, diketahui bahwa jumlah tabel yang diperlukan dalam database berjumlah tiga buah. Untuk userinterface dihasilkan sebanyak tujuh buah baik layar input maupun output dari sistem. Tahap implementasi menjabarkan penterjemahan sistem yang dibangun dengan menggunakan bahasa pemrograman Joomla. Untuk tahap terakhir yaitu integrasi dan pengujian sistem, sistem yang dibangun diuji dengan menggunakan metode pengujian White Box dan Black Box.

\section{Saran}

Ada beberapa hal yang perlu disampaikan agar menjadi bahan pertimbangan untuk melengkapi penelitian dimasa mendatang. Halhal tersebut diungkapkan dalam bentuk saran seperti berikut:

a. Jika diperlukan, sistem untuk prediksi kanker payudara ini dapat dikembangkan lebih lanjut dengan menggunakan kombinasi dari hasil sistem yang berjalan agar lebih akurat data yang dihasilkan.

b. Aplikasi dapat dikembangkan agar tidak hanya menjadi prototype saja, melainkan diimplementasikan dalam proses pendeteksian secara nyata agar dapat memberikan kemudahan dalam proses prediksi kanker payudara pada pasien. 


\section{Daftar Pustaka}

Dudek, Gabriela. (2012), " Fuzzy Analysis Of The Cancer Risk Factor", Department of Physical Chemistry and Technology of Polymers Silesian University of Technology Poland volume 43.

Hidayat, Nurul. (2007), "Desain Sistem Pakar Fuzzy Untuk Diagnosa Kanker Prostat", Seminar Nasional Teknologi Fakultas Sains dan Teknik Universitas Jenderal Soedirman.

Kusumadewi, Sri. (2009), "Logika Fuzzy", GEMATIKA Jurnal Manajemen Informatika.

Nugroho, Eddy Prasetyo. (2009), "Rekayasa Perangkat Lunak", Politeknik TELKOM.

Nurjadi, Joko. (2009), "Membangun Website dengan Joomla", PC Media.

O’Docherty, Mike. (2005), “Object-Oriented Analysis and Design: Understanding System Development with UML 2.0", John Wiley \& Sons, Inc.

Pressman, Roger S. (2010), "Software Engineering : A Practitioner's Approach", McGraw-Hill Companies, Inc.

Roche (2000). "Kanker Payudara”, WHO

Ross, Timothy J. (2010), "Fuzzy Logic with Engineering Application”, John Wiley \& Sons, Ltd.

Saleh, Ahmed. (2011), "A Fuzzy Decision Support System for Management of Breast Cancer", International Journal of Advanced Computer Science and Applications Vol. 2 No.3 Dept. of Information Systems Faculty of computer and information system Mansoura University Mansoura Egypt.

Santoso, Leo Willyanto. (2009), " Implementasi fuzzy expert system untuk analisis penyakit dalam pada manusia”, Seminar Nasional Aplikasi Teknologi Informasi.

Sommerville, Ian. (2011), "Software Engineering", Pearson Education, Inc.

Siler, William. (2005), "Fuzzy expert systems and fuzzy reasoning", John Wiley \& Sons, Inc.

Sukla, Anupam. (2010), " Real Life Applications of Soft Computing", Taylor and Francis Group, LLC.

Syarifudin. (2012), “Web Professional”, Ebook. 